\title{
Humor Styles, Positive Personality and Health
}

\author{
Arnie Cann \\ Univ ersity of North Carolina Charlotte \\ Charlotte, North Carolina, USA
}

Kelly Stilwell

University of North Carolina Charlotte

Charlotte, North Carolina, USA

\section{Kanako Taku}

Oakland University

Rochester, Michigan, USA

\begin{abstract}
The research examines the relationship of sense of humor differences and positive personality qualities with perceptions of stress and well-being. Positive and negative styles of self-directed humor were assumed to have opposing relationships with perceived stress, but the relationships were predicted to be mediated through positive personality qualities. University students provided data at two points in time separated by 8 weeks. Data from time 1 was used to verify the mediation of the relationship of sense of humor with perceived stress through the positive personality qualities. A more extensive theoretical model, using longitudinal data, was tested using the sense of humor measures from time 1 and positive personality qualities at time 2 to predict perceived stress and well-being at time 2. The results from the two analyses support the proposed mediator model in which the potential health benefits of a positive humor style and the potential damage to health associated with a negative humor style are mediated through the positive personality qualities. Thus, it would appear that good humor uses can support maintaining a stable positive personality style, which has positive associations with both psychological and physical well-being.
\end{abstract}


Keywords: sense of humor, positive personality, psychological well-being, physical wellbeing

A good sense of humor has long been imagined to be a personal quality that can moderate the impact of stressors in one's life (Lefcourt \& Martin, 1986; Lefcourt, 2001). A sense of humor, it has been suggested, can help a person engage in positive reframing, and creative reinterpretation of events to limit or dispel the negative affect associated with stressors (e. g. Abel, 2002; Abel \& Maxwell, 2002; Kuiper \& Olinger, 1998; Nezu, Nezu, \& Blissett, 1988). Support also comes from research indicating that a good sense of humor has been associated with higher levels of cheerfulness (Martin, Puhlik-Doris, Larsen, Gray, \& Weir, 2003) and positive affect (Celso, Ebener, \& Burkhead, 2003) and lower levels of negative affect and depression (Anderson \& Arnoult, 1989; Overholser, 1992). However, the results have not been consistent in confirming these positive relationships (see Martin 2007 for a recent overview). In quite a number of cases there has been little or no relationship found between the assessments of sense of humor and indicators of psychological health (e. g., Kuiper, \& Borowicz-Sibenik, 2005; Kuiper \& Martin, 1998a; 1998b; Porterfield, 1987).

A similar body of research exists when looking at the potential relationship between humor, sense of humor, and physical health indic ators. Studies have found exposure to humor had positive physiological effects (e.g. Berk et al., 1989; Berk, \& Tan, 2009; Lefcourt, Davidson-Katz, \& Kueneman, 1990). However, other investigations report no relationship (e. g., Harrison et al., 2000; Kerkkanen, Kuiper, \& Martin, 2004; Njus, Nitschke, \& Bryant, 1996). In research on health symptom reporting, there also are examples of supportive findings (e.g., Carroll \& Shmidt, 1992; Ruch \& Kohler, 1999) and findings that fail to confirm a relationship (Labott \& Martin, R. B., 1987; Porterfield, 1987). In fact, in a recent review of the literature (Martin, 200 1; 2004) the overall pattern of results did not support a reliable relationship between humor variables and physical health related indic ators.

Virtually all of the research cited above looking at sense of humor and health, even in instances where multiple measures of sense of humor were used in a study, focused on sense of humor as if it is exclusively a positive, adaptive quality. Although other less positive forms of humor, involving sarcasm, ridicule, teasing and other forms of disparagement have long been recognized as common (Janes \& Olson, 2000; Zillman, 1983), the available measures of sense of humor have not adequately captured these styles of humor. Recent developments in the assessment of sense of humor (Martin et al, 2003), reflecting an appreciation for the positive or adaptive uses of humor and the less adaptive or negative uses, have provided an opportunity 
to clarify the potential relationships between sense of humor and psychological and physical health. The Humor Styles Questionnaire (HSQ: Martin et al., 2003) provides a more comprehensive assessment of the multiple styles of humor that have been observed. The HSQ identifies four humor styles, including styles that could exacerbate stress rather than reduce it. The affiliative humor style, characterized by entertaining and supporting others through humor is most like the previous measures of sense of humor that focused on the positive uses of humor. An aggressive humor style reflects individuals' use of humor to tease or demean others, in order to gain some status for oneself. A tendency to use this style of humor can be damaging to interpersonal relationships (Cann, Zapata, \& Davis, 2009; in press). Of most importance to understanding the potential role of humor styles in limiting the negative impact of stressors are the two humor styles that are self-directed rather than focused on others. Self-enhancing humor is closely related to the notion of coping humor (Martin, 1996; Martin et al, 2003), and is characterized by uses of humor to maintain a positive outlook on life and to cope with stressors by finding new perspectives for interpreting them. Self-defeating humor, on the other hand, inv olves ridicule or demeaning of the self in an effort to gain favor with others, a style that has been found to be associated with higher levels of anxiety and depression (Martin et al., 2003) and has the potential to lower rather than raise one's positive affect.

In a number of recent investigations, these two self-directed humor styles have demonstrated opposing relationships with health related outcome variables. Kuiper, Grimshaw, Leite, and Kirsh (2004) looked at a number of well-being indicators and found a low self-enhancing style was associated with lowered well-being. In addition, they reported that a high self-enhancing style was positively related to multiple self-competencies associated with better coping. The self-defeating style, on the other hand, was positively related to reported depression and anxiety and negatively associated with the self-competencies. Hugelshofer, Kwon, Reff, \& Olson (2006) found the same pattern looking at the two styles relationships with levels of depression, and Chen and Martin (2007) reported a similar pattern when looking at mental health based on self reported symptoms. Cann and Etzel (2008) looked at ratings of perceived stressors in one's life and found self-enhancing humor was negatively related, and self-defeating was positively related to both evaluations of past stressors and anticipated future stressors. Clearly the two self-directed styles of humor are not both adaptive, greater tendencies to use a self-defeating humor style appears to be associated with poorer adjustment and lower well-being. Although there was also evidence of a positive relationship between affiliative humor style and well-being in some of these studies, in both Chen and Martin (2007) and Cann and Etzel (2008), when the four humor styles were entered together in a regression 
model, only the self-directed styles were reliably related to the well-being outcome measures.

Taken together, these studies provide considerable support for the importance of assessing sense of humor as a multidimensional variable, with elements that can be either positive or negative factors in predicting health and well-being and in influencing other experiences. Although additional research will be necessary, this more comprehensive conceptualization of sense of humor may lead to a more consistent pattern of findings in relationships between humor uses and health outcomes. However, even if the pattern does become clearer, the question remains as to how these humor styles actually influence psychological and physical health. One possibility is that effective use of humor, for example higher uses of selfenhancing and lower uses of self-defeating humor, may operate through their impact on more global differences in the tendency to experience positive or negative affect. The humor styles have been shown to be related to measures of typical positive and negative affect (Kuiper et al., 2004), and to more enduring qualities like optimism, cheerfulness and bad mood (Martin et al., 2003), and sociotropy (Frewen, Brinker, Martin, \& Dozois, 2008). Cann and Etzel (2008) found the humor styles explained a significant amount of the variability in three separate qualities associated with positive personality (optimism, hope, and happiness), with the two self-directed styles consistently significant as individual predictors.

The literature on the relationship between stable differences in affectivity and health is generally more consistent than the findings to date for the role of sense of humor as a predictor of health. Chronic negative affect has been shown to be related to poorer health experiences (Friedman \& Booth-Kewley, 1987), and recent levels of negative affect (Kuiper \& Harris, 2009) were a better predictor of physical health than were the humor styles based on the HSQ. The presence of positive affect as a stable state also has been found to be associated with positive health experiences. Positive emotional styles were associated with better immune response (Cohen, Doyle, Turner, Alper, \& Skoner, 2003; Cohen, Alper, Doyle, Treanor, \& Turner, 2006). Consistently higher levels of positive affect also are associated with greater psychologic al resilience (Cohn, Frederickson, Brown, Mikels, \& Conway, 2009), fewer illness symptoms reported (Pettit, Kline, Gencoz, Gencoz, \& Joiner, 2001), and better health in general (Pressman \& Cohen, 2005). People who are high on positive personality qualities tend to report experiencing more consistent and higher levels of positive affect and lower levels of negative affect. These positive personality qualities also are associated with more positive approaches to coping in stressful situations and better overall health. Research supports the health benefits of greater optimism (Carver, Scheier, \& Miller, 2009), higher levels of hope as a stable trait 
(Richman, Kubzansky, Maselko, Kawachi, Choo, \& Baver, 2005), and stable differences in happiness (Siahpush, Spittal, \& Singh, 2008; Veenhoven, 2008). In general, these positive personality qualities have been more reliable predictors of health and effective coping than have measures of sense of humor. However, these qualities, positive personality styles and humor styles, may be linked since maintaining a consistent positive outlook would seem to require behaviors that support that state. Effective use of humor may be one way that people with more positive personality qualities maintain their positive outlooks.

In a recent study (Cann \& Etzel, 2008), initial evidence was found to support a mediator model in which the role of humor styles in explaining perceptions of stress was mediated through a composite of positive personality styles (optimism, hope, and happiness). The current research seeks to extend those findings in two ways. First, the mediator model will be examined by considering each positive personality quality as a separate mediator rather than the composite based on all three qualities. Secondly, a hypothesized model will be tested to see if the results of the mediator analyses are validated using longitudinal data and if the reported perceived stress does translate into different levels of self-reported psychological and physical health. To better capture the assumed role of the humor styles, a longitudinal model will be tested, using humor styles at time 1 but positive personality, and perceived stress at time 2. A checklist of actual stressors experienced during the interval will provide an additional validation of perceived stress as a reflection of actual life events.

\section{Method}

\section{Participants}

Participants were enrolled in undergraduate psychology courses at a university in the southeastern United States and they received credit toward a course requirement by participating in research opportunities. At time 1, 299 participants (58 men and 241 women) completed the on-line questionnaires. All participants were at least 18 years of age $(M=20.86, S D=5.67)$, and the vast majority classified themselves as Caucasian (223, 45 Black, 16 Asian, 9 Hispanic, 6 other). At time 2, 174 participants (30 men and 144 women) completed the questionnaires. The mean age of this group was 20.92 years (SD $=5.95$ ) and the vast majority were Caucasian (137, 22 Black, 8 Asian, 4 Hispanic, 3 other). Those who completed both sets of measures ( $\mathrm{n}=$ 174) were compared to those who only completed the measures at time $1(N=125)$ on the demographic variables (age, gender, ethnic group) and on all measures 
collected at time 1. There were no statistically reliable differences on any of these variables.

Measures

Humor Styles Questionnaire (HSQ). The Humor Styles Questionnaire (Martinet al., 2003) assesses individual differences in four styles of humor use. Two styles are primarily other-directed; with aggressive humor involving humor that attacks or demeans others and affiliative humor characterized by efforts to build relationships through humor. The other two styles are self-directed; with self-defeating humor characterized by humor that demeans the self in efforts to build relationships and self-enhancing humor designed to protect or amuse oneself with humor. Eight items assess each humor styles, with responses provided on a scale ranging from 1 (totally disagree) to 7 (totally agree) and scores reported as means on that scale. This questionnaire, including each of the four styles of humor measured, has been shown in previous work to have construct validity and to have good internal reliability (alphas ranging from .77 to .81) (Martin et al., 2003).

Positive Personality Measures

The Life Orientation Test-Revised (LOT-R). The Life Orientation Test-Revised is a 10item questionnaire designed to assess generalized dispositional optimism. It consists of 6 relevant items and 4 non-relevant items that are rated from 0 (I disagree a lot) to 4 (I agree a lot) (Scheier, Carver, \& Bridges, 1994). This questionnaire measures an individual's degree of optimism with scores reported as the mean rating of the 6 relevant items. The LOT-R has been shown to have good internal reliability (alpha $=$ .83; Scheier et al., 1994).

The Hope Scale (HOPE). The Hope Scale is a 12-item questionnaire that includes 8 relevant items and 4 non-relevant items (Snyder et al., 1991). The HOPE measures two dimensions of trait-based hope: Agency (the strong belief that one will meet their goals) and Pathways (the belief that one will find the path to reach their goals). A single hope score, based on combining these two dimensions of hope, will be used to characterize dispositional differences in global hope. Responses to items are on a 4-point scale (Definitely False - 1 to 4 - Definitely True) and scores are reported as means on that scale. The full scale has shown acceptable internal reliability (alphas $\geq .74$; Snyder et al., 1991).

Oxford Happiness Questionnaire-Short Form (OHQ-SF). The short form of the Oxford Happiness Questionnaire (Hills \& Argyle, 2002) is an 8-item questionnaire designed to capture stable differences in personal happiness and a sense of well being. 
Responses are provided on a scale from 1 (strongly disagree) to 6 (strongly agree) and scores are reported as the mean rating of the 8 items. The full 20 item $\mathrm{OHQ}$ scale has excellent internal reliability (alpha $=.91$ ) and the short form correlates strongly with the full scale $(r=.90)$. Internal reliability for the HHQ-SF was good in the current sample (alpha $=.82$ ).

\section{Assessment of Actual and Perceived Stressors}

Inventory of College Students' Recent Life Experiences (ICSRLE). The Inventory of College Students' Recent Life Experiences (Kohn, Lafreniere, \& Gurevich, 1990) is a 37-item questionnaire that presents a list of common events that have been shown to be potential stressors in college students' lives. A factor analysis of the scale produced a 37 item version that contain 7 factors: developmental challenge, time pressure, academic alienation, romantic problems, assorted annoyances, social mistreatment, and friendship problems. A subsequent confirmatory factor analysis has confirmed these 7 domains (Osman, Barrios, Longnecker, \& Osman, 1994). For each event, the responses range from 1 (not at all part of my life) to 4 (very much part of my life) and overall scores are presented as the mean rating. Participants rated the events based on their experiences in the past month. The internal reliability of this inventory was found to be good (alpha =.89; Kohn, et al., 1990 and alpha = .92; Osman et al., 1994).

Perceived Stress Scale (PSS). The Perceived Stress Scale is a 14-item questionnaire that provides a global assessment of the level of stress people perceive to be present in their lives recently (Cohen, Kamarck, \& Mermelstein, 1983). Responses to individual items range from 0 (never) to 4 (very often) and the sum of the 14 items is used as the measure of stress, so scores can vary from 0 to 56 . In a current study, participants reported on the perceived stressors over the past month. Internal consistency has been good in previous examinations (alphas $\geq .84$; Cohen et al., 1983).

\section{Assessment of Psychological and Physical Health}

The Short-Form-36 Health Survey has been used extensively in health research (SF36; Ware, Snow, Kosinski, \& Gandek, 1993) and it includes 36 items that measure eight dimensions of health. These dimensions reflect two general domains General Physical Health and General Psychological Health. General Physic al Health includes the dimensions physical functioning, role limitations due to physical health problems, bodily pain, and general health perceptions. General Psychological Health includes 
the dimensions social functioning, mental health, role limitations due to emotional problems, and vitality (energy or fatigue) (Ware et al., 1993). For most of the items, the instructions ask that the respondent focus on the past 4 weeks, although some items refer to a typical day. The internal reliability coefficients have been reported by many studies for this survey (for review see Ware et al., 1993). In review of these studies, it was found that the internal reliability coefficients median exceeded .80 for all scales except for the social functioning scale which was .76 (Ware et al., 1993). Recent examinations of the scale on large samples using factor analysis and SEM have confirmed the two main domains and eight dimensions (Anagnostopoulos, Niakas, \& Tountas, 2009). All of the SF36 scores are transformed to 0 to 100 scales, with higher scores indic ating better physical or psychological health.

\section{Procedure}

The measures were completed using an on-line survey system. Available studies are listed on a web site, and students seeking research opportunities choose from the list. This study was described as a two-part study on how people's personality and interaction style were related to how they interpret events and react to those events. Part 1 of the study was available for the first two weeks of the semester. When participants decided to participate, they were directed to the web survey where they first viewed an informed consent statement. After agreeing to continue, they completed a series of demographic questions (age, sex, race, marital status) followed by the measures, presented in random order for each participant. At time 1 the measures included the HSQ, LOT-R, HOPE, OHQ-SF, and the PSS. Eight weeks after the first phase was ended, email messages were sent to the participants inviting them to complete part two. At time 2 participants completed the LOT-R, HOPE, OHQ-SF, and the PSS, along with the SF36 and the ICSRLE.

\section{Results}

Time 1

The descriptive statistics, internal reliabilities, and correlations among variables for all measures collected at Time 1 are in Table 1. The purpose of the Time 1 analyses was to demonstrate the mediator roles played by the three positive personality qualities in helping to understand the relationship between humor styles and perceived stress in one's life. Using a bootstrapping technique, and an SPSS macro program that allows for the examination of multiple potential mediators (Preacher \& Hayes, 2008), the analyses provide a replication and extension of the findings reported by Cann 
and Etzel (2008) using a more powerful and sensitive statistical strategy. These analyses allow for separate assessments of each positive personality quality as a mediator and a comparison of the mediation effects between the three qualities. In Cann and Etzel (2008) only the two self directed humor styles were found to be reliable predictors of perceived stress, and a multiple regression on the current data (predicting PSS from the four HSQ scores) confirmed this finding, so only the two self directed styles were examined in separate mediation analyses.

Table 1

Descriptive Statistics, Internal Reliabilities, and Correlations for All Measures Collected at Time 1 ( $n=299)$.

Measure Mean (SD) HSQaff HSQagg HSQse HSQsd HOPE OHS-SF LOT-R PSS HSQ aff $5.62(0.93) \quad .73$

HSQagg $3.34(0.99) \quad .16^{*} \quad .74$

HSQse $4.53(1.16) \quad .46 * \quad .05 \quad .87$

$\begin{array}{llllll}\text { HSQsd } & 3.17(1.14) & .06 & .27^{*} & .06 & .84\end{array}$

$\begin{array}{lllllll}\text { HOPE } & 3.16(0.40) & .19 * & -.14 & .35^{*} & -.24 * & .82\end{array}$

OHS-SF

$4.45(0.83) \quad .22 * \quad-.08$

LOT-R

$2.55(0.78) \quad .14 \quad-.20 *$

$.41^{*} \quad-.25^{*}$

$.51 *$ .78

PSS

$24.86(7.68)-.19 * \quad .12$

$.45^{*}-.30^{*}$

$.46 * \quad .57 * \quad .82$

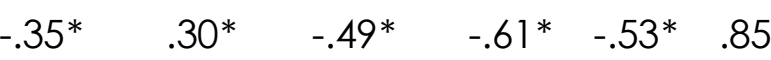

Note: Values on the diagonal are internal reliabilities (Cronbach alphas). The Humor Style scores (HSQ) represent the affiliative (aff), aggressive (agg), self enhancing (se) and self defeating (sd) styles, and are on 7-point scales from totally disagree (1) to totally agree (7). HOPE scores are on a 4-point scale from definitely false (1) to definitely true (4). Happiness scores (OHS-SF) are on a 6-point scale from strongly disagree (1) to strongly agree (6). Optimism (LOT-R) scores are on a 5-point scale from I disagree a lot (0) to I agree a lot (4), and higher scores indicate greater optimism. The Perceived Stress Scale (PSS) scores are the sum of 14 items rated on a 5-point scale from never (0) to very often (4), so scores can range from 0 to 56 . Higher score indicate greater perceived stress.

$* p<.01$

The bootstrapping analyses use 5000 re-samples to generate the coefficients and the bias corrected 95\% confidence intervals (Preacher \& Hayes, 2008). For the Selfenhancing humor style, the desirable prerequisite conditions for potential mediation were present. Self-enhancing humor style was a significant predictor of perceived stress, and of each positive personality quality, and each positive personality quality was also a significant predictor of perceived stress when controlling for selfenhancing humor ( $\mathrm{p}$ 's all < .001). The indirect effects evaluating mediation are 
shown in Table 2. The results for Total show the change (direct path versus mediated path) in the regression coefficient for self-enhancing humor due to the mediation, and it indicates that self-enhancing humor is significantly mediated through the three positive personality qualities. The regression coefficient for self-enhancing humor $(b=-0.185)$ was no longer significant $(p=.58)$ after the mediators were included. The results for the positive personality qualities indicate that all three were individually significant as mediators. In comparing the relative strengths of the mediation effects, the specific effects of OHS-SF were greater than those for HOPE, but no other differences among the me diators were statistically reliable. Thus, while the positive personality qualities in general mediate the relationship between selfenhancing humor and perceived stress, it also is the case that each quality alone operates as a reliable mediator.

Table 2

Mediation Results for Self-enhancing Humor Styles.

\section{Bias Corrected $95 \% \mathrm{Cls}$}

Total

Coefficient SE

Lower Upper

OHS-SF

$-2.101 * \quad .286$

$-2.685$

$-1.558$

LOT-R

$-0.998 * \quad .199$

$-1.431$

$-0.643$

HOPE

$-0.651 * \quad .178$

$-1.027$

$-0.325$

OHS-SF - LOT-R

$-0.452 * \quad .141$

$-0.773$

$-0.215$

OHS-SF - HOPE

$-0.347$

.281

$-0.932$

0.192

LOT-R - HOPE

$-0.545^{*}$

.249

$-1.050$

$-0.070$

$* p<.05$

$-0.199 \quad .225$

$-0.659$

0.225

For the Self-defeating humor style, the desirable prerequisite conditions for potential mediation also were evident. Self-defeating humor style was a significant predictor of perceived stress, and of each positive personality quality, and each positive personality quality was also a significant predictor of perceived stress when controlling for self-defeating humor style ( $p$ 's all <.001). Table 3 contains the results evaluating the indirect effects for assessing potential mediation. The results for Total show the change in the coefficient for self-defeating humor due to the mediation through all three positive personality qualities and it indicates a significant mediation relationship. In this case, although the coefficient for self-defeating humor was significantly reduced due to the mediation, there was still a significant relationship for self-defeating humor and perceived stress $(b=0.651, p=.04)$, suggesting only partial mediation. Once again the results for the positive personality qualities indicated that 
all three were individually significant as me diators. There were no reliable differences in the indirect effects when comparing the individual mediators. Consistent with the results for self-enhancing humor, the positive personality qualities in general mediate the relationship between self-defeating humor and perceived stress, and each quality alone operates as a reliable mediator.

Table 3

Mediation Results for Self-defeating Humor Styles.

\begin{tabular}{lcccc} 
& & \multicolumn{3}{c}{ Bias Corrected 95\% Cls } \\
& Coefficient & SE & Lower & Upper \\
Total & $1.344^{*}$ & .272 & 0.831 & 1.898 \\
OHS-SF & $0.626^{*}$ & .175 & 0.831 & 1.898 \\
LOT-R & $0.420^{*}$ & .135 & 0.199 & 0.738 \\
HOPE & $0.298^{*}$ & .121 & 0.114 & 0.586 \\
OHS-SF-LOT-R & 0.206 & .211 & -0.184 & 0.650 \\
OHS-SF-HOPE & 0.327 & .205 & -0.077 & 0.729 \\
LOT-R - HOPE & 0.122 & .172 & -0.212 & 0.474 \\
${ }^{*} \mathrm{P}<.05$ & & & &
\end{tabular}

Time 2

The SEM analysis involves a longitudinal approach looking at the humor style scores from time 1 as they relate to both the positive personality measures and the perceived stress scores at time 2 (see Table 4 for descriptive statistics and correlations).

Table 4

Descriptive Statistics, Internal Reliabilities, and Correlations for Humor Styles, Positive Personality, and Perceived Stress Measures Used at Time 2 ( $n=174)$.

Measure Mean (SD) HSQaff HSQagg HSQse HSQsd HOPE OHS-SF LOT-R PSS HSQaff T1 $5.61(0.91) \quad .70$

HSQagg T1 $3.34(0.92) \quad .23 * \quad .70$

HSQse T1 $4.62(1.14) \quad .45^{*} \quad .10 \quad .88$

$\begin{array}{llllll}\text { HSQsd T1 } & 3.27(1.05) & -.02 & .35^{*} & .12 & .81\end{array}$

$\begin{array}{lllllll}\text { HOPE T2 } & 3.11(0.45) & .19 & -.10 & .35^{*} & -.19 & .84\end{array}$

$\begin{array}{llllllll}\text { OHS-SF T2 } & 4.36(0.85) & .18 & -.08 & .37^{*} & -.24^{*} & .62^{*} & .79\end{array}$

$\begin{array}{lllllllll}\text { LOT-R T2 } & 2.51(0.83) & .10 & -.24^{*} & .37^{*} & -.25^{*} & .55^{*} & .70^{*} & .86\end{array}$ 
PSS T2 $25.28(7.43) \quad-.14 \quad .10 \quad-.29 * \quad .24 * \quad-.59 * \quad-.61^{*}-.62 * \quad .85$

Note: Values on the diagonal are internal reliabilities (Cronbach alphas). The Humor Style scores (HSQ: from Time 1) represent the affiliative (aff), aggressive (agg), self enhancing (se) and self defeating (sd) styles, and are on 7-point scales from totally disagree (1) to totally agree (7). HOPE scores are on a 4-point scale from definitely false (1) to definitely true (4). Happiness scores (OHS-SF) are on a 6-point scale from strongly disagree (1) to strongly agree (6). Optimism (LOT-R) scores are on a 5-point scale from I disagree a lot (0) to I agree a lot (4), and higher scores indicate greater optimism. The Perceived Stress Scale (PSS) scores are the sum of 14 items rated on a 5-point scale from never (0) to very often (4), so scores can range from 0 to 56 . Higher score indicate greater perceived stress.

$* p<.01$

In addition, participants completed the ICSRLE to provide information about the actual stressors experienced during the past month. The ICSRLE and the PSS for time 2 were strongly correlated $(r=.60, p>001)$, indicating that the PSS scale does capture the effects of actual events experienced. The model also includes separate assessments of both psychological and physical well being (see Table 5 for descriptive statistics for the ICSRLE and well-being measures).

Table 5

Psychological and Physical Health Indicators and Stressors Reported at Time 2

$\begin{array}{lll}\text { Measure } & \text { Mean } & \text { SD } \\ \text { ICRLES Total } & 2.11 & 0.43 \\ \text { Developmental Challenges } & 2.35 & 0.56 \\ \text { Time Pressure } & 2.43 & 0.62 \\ \text { Academic Alienation } & 2.16 & 0.81 \\ \text { Romantic Problems } & 2.02 & 0.72 \\ \text { Social Mistreatment } & 1.86 & 0.62 \\ \text { Assorted Annoyances } & 1.67 & 0.49 \\ \text { Friendship Problems } & 1.80 & 0.67 \\ \text { General Psychological Health } & 68.90 & 16.27 \\ \text { Social Functioning } & 78.16 & 23.30 \\ \text { Emotional Role Limitations } & 76.68 & 22.79 \\ \text { Vitality } & 55.93 & 16.79 \\ \text { Mental Health } & 64.83 & 16.79 \\ \text { General Physical Health } & 82.02 & 15.07 \\ \text { Physical Role Limitations } & 86.57 & 20.15 \\ \text { Bodily Pain } & 80.75 & 20.01\end{array}$




$\begin{array}{lll}\text { Physical Functioning } & 90.29 & 16.58 \\ \text { Physical Health } & 70.46 & 19.28\end{array}$

Note: ICSRLE scores indicate the presence of stressors (1-not at all to 4-very much). Health scores, from the SF36 are on a 0 to 100 scale, with higher scores indicating better health.

Based on the findings from the previous work (Cann \& Etzel, 2008) and the results from Time 1 mediation analyses, a model was developed and tested using Structural Equation Modeling by AMOS (Arbuckle, 1994-1999). The model was estimated with maximum-likelihood estimation and included the following seven latent variables: self-enhancing and self-defeating humor styles assessed at Time 1, positive personality at Time 2 that was explained by three observed variables (optimism, happiness, and hope), perceived stress at Time 2, stressful experiences assessed at Time 2, and two health outcomes (physical and psychological) at Time 2. Specifically, as shown in Figure 1, with the mediation through positive personality qualities, two self-directed humor styles (self-enhancing and self-defeating) assessed at $\mathrm{Tl}$ predicted perceived stress at Time 2, which in turn predicted health outcome (physical and psychological health) at Time 2 in the model.

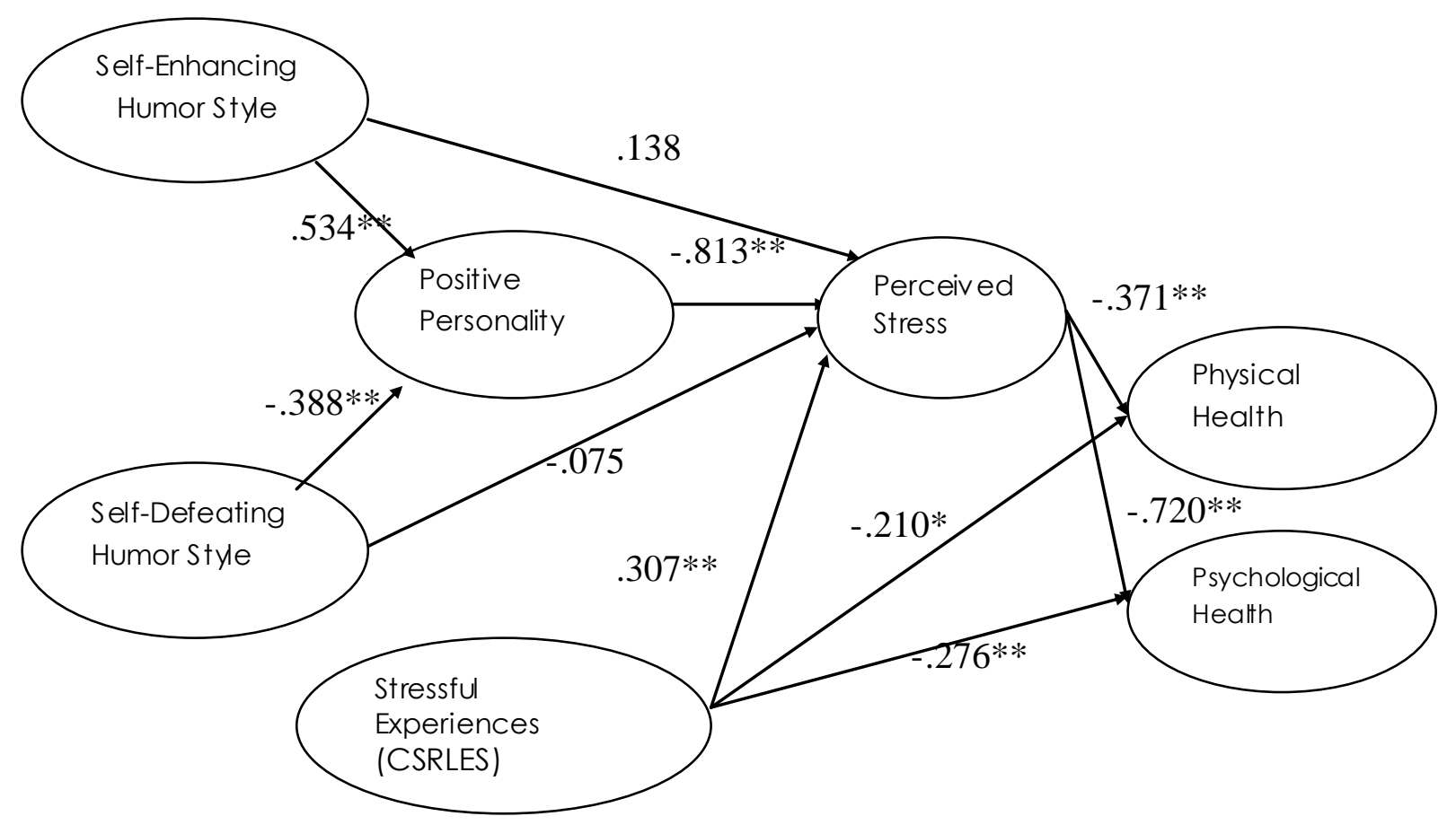

Figure 1. Hypothesized mo del of two self-directed humor styles leading to perceived stress mediating by positive personality.

$p<.05^{*}, p<.001^{* *}$

The overall model fit was assessed using the following indices. As the CFI and TLI values of greater than .95 and the RMSEA value of .06 or less indicates an 
acceptable fit (e.g., Hu \& Bentler, 1999), the current model was shown to be satisfactory $\left(X^{2}(1162)=2107.53, p<.01, C F I=.957, \mathrm{TLI}=.952, \mathrm{RMSEA}=.069\right)$. The model assumed the covariance among the predictors $(r=.108$, n.s., between selfenhancing humor style and self-defeating humor style; $r=-.245, p<.01$, between self-enhancing humor style and stressful experience; and $r=.431, p<.01$ between self-defeating humor style and stressful experience). The standardized regression weights showed that the positive personality composite mediated the relationships between self-enhancing/self-defeating humor styles and perceived stress, and that the perceived stress coupled with the stressful experiences predicted the health outcomes. Not surprisingly, the strength of the relationship between perceived stress and psychological well-being was much stronger that the relationship with physical health. Given that the paths from two humor styles leading to perceived stress were not significant (.138 for self-enhancing humor style to perceived stress; - .075 for selfdefeating humor style to perceived stress), the mediating role of positive personality qualities in the longitudinal process of humor style predicting the perceived stress was supported.

\section{Discussion}

Is a good sense of humor related to more positive reported levels of health? The research to date has provided mixed results for both reports of psychological well being and for physical health. The current results suggest that a more complex approach to the question may be needed to more clearly identify the role that sense of humor might play. First, the results add to the growing literature that supports the essential importance of a multidimensional approach to sense of humor as a personal quality. Although a number of sense of humor measures had acknowledged that there are multiple ways in which a sense of humor might be expressed by an individual (e.g. Svebek, 1996; Thorson \& Powell, 1993), little systematic attention had been paid to measuring the tendencies to engage in the potentially negative forms of humor. The Humor Styles Questionnaire (Martin et al., 2003) corrects this deficiency, capturing both positive and negative uses of humor, and identifying humor styles that may be dysfunctional in some circumstances.

In considering the role of sense of humor in an individual's attempts to deal with life's stressors, the distinctions provided by the HSQ are critical. Humor styles that are selfdirected are much more important in understanding how people respond to potential stressors than are those humor styles that tend to be focused on others. Furthermore, self-directed humor that demeans the self actually is positively related to the levels of stress experienced, and therefore, negatively related to self-reported 
health. Only the self-enhancing humor style appears to buffer the effects of stressors in the way many researchers have speculated sense of humor should operate. Sense of humor measures that do not account for these important differences in how humor is used are likely to lead to inconsistent results. The question that needs to be asked is not whether a good sense of humor is related to greater well being, but rather, does the person's style of using humor facilitate or inhibit the potential to deal effectively with stressors through humor. Not all styles of humor are relevant to this question, and not all styles of humor are likely to yield positive relationships with well being. For those who rely heavily on a self-demeaning humor style to express their sense of humor, their sense of humor predicts lower, not higher, well being.

Our results, and other recent findings (Cann \& Etzel, 2008; Chen \& Martin, 2007) also suggest that other-directed humor styles are of little importance in understanding the relationship between sense of humor and health outcomes, especially after controlling for variance explained by the self-directed styles. The other-directed uses of humor are still potentially important to consider as personal qualities, but their relevance likely will be greater when the uses of humor are directed toward interpersonal, rather than intrapersonal, goals. For example, in a recent study looking at relationship satisfaction in dating couples (Cann, Zapata, \& Davis, 2009; in press), the two other-directed humor styles explained much more variance than the self-directed styles. Once again, however, the additional distinction between positive and negative uses of humor was critical, since affiliative and aggress styles had opposing relationships with the couples' satisfaction. What is clear from this emerging body of research is that humor styles, as expressions of a sense of humor, cannot be looked at as uniformly positive. The 'dark side' of humor uses must be appreciated since it can potentially be as disruptive a factor as positive uses of humor can be constructive. As much as a 'good' sense of humor, represented by the positive uses of humor, may allow for more effective handling of stressors, better well being and more positive relationships, so too can the negative styles of humor lead to increases in perceived stress, lowered well being, and disruption of relationships.

The second contribution of the current results is providing a model that offers the potential for refining our understanding of the actual processes through which effective and ineffective styles of humor may be relevant to psychological and physical well being. The proposed mediator model assumes that the positive role that sense of humor can play in promoting well being can best be understood by considering humor styles as supporting the more global and stable positive personality qualities of an individual. Using humor effectively, through higher levels of 
self-enhancing humor and lower levels of self-demeaning humor, can help to maintain a more positive personal style, characterized by higher positive affectivity and by qualities like optimism, happiness, and hope. Thus, it was shown that these three different positive personality qualities each served as a mediator of the relationship between humor styles and perceptions of stress. In most of the mediator analyses, the direct relationship between humor styles and perceived stress was negligible after introducing the positive personality qualities. The mediation was apparent for both the positive humor style and the negative humor style. Only when sense of humor contributes to maintaining these positive personality qualities will it be relev ant to more positive health, and its relationship is more indirect than direct.

The current findings replicate, but also extend findings reported by Cann and Etzel (2008). While they were able to show that a composite measure of positive personality mediated the relationship of humor styles with perceived stress, our analyses indicate that each separate positive personality quality operates as a potential mediator. In addition, our results were able to demonstrate that the mediator relationship was further supported within a model that incorporated longitudinal data, assessed both perceived stressors and stressors actually experienced, and included psychological and physical well-being outcomes. Humor styles assessed eight weeks earlier were still mediated by current levels of positive personality. In addition, the longitudinal approach supported the utility of the perceived stress measure as an indicator of actual stressors exposed to over time. The checklist of stressors experienced during the interval between the two assessments was highly correlated with the reported levels of perceived stress. Although both actual stressors experienced, based on the checklist, and perceived stress were reliably related to the health self-reports, the relationships were stronger for the perceived stress, supporting the notion that the individual's construal of the stressful experience is critical in understanding the impact the experience has on well being. Also, not surprisingly, the perceived stressors were more strongly related to self-reported psychological health than to reported physical health. How a person frames or interprets events may not be able to alter as easily actual pain or levels of physical functioning, but it could more easily influence how you psychologically adjust to your condition.

In summary, the proposed model indicates that sense of humor can be a useful social quality in facilitating well being, but that its role may be primarily as a style of thinking and behaving that promotes and supports a more general positive personality style. Using self-directed humor effectively can help to maintain higher levels of positive personality traits, which are associated with stable tendencies to 
see the world more positively. People who evidence stable higher levels of optimism, hope, and happiness, supported by a good sense of humor, tend to perceive their lives as less stressful, and therefore report more positive levels of both physical and psychological health.

Future research should consider how differences in humor styles might play a role in the more global processes connecting stable differences in underlying self views to social and psychological outcomes. In the current examination of humor styles, the focus has been on how the humor styles relate to the perceptions of life stressors. In this role, the importance of humor styles appears to be mediated through stable positive personality qualities. However, a number of recent studies also have found that humor styles can be mediators of relationships between underlying self-concept indicators and both social and psychological outcomes. For example, the affiliative humor style served as a mediator between the attachment style of anxiety and relationship satisfaction (Cann, Norman, Welbourne, \& Calhoun, 2008). Other recent studies have found that humor styles mediate some relationships between positive and negative self-evaluation standards and both social self-esteem and depression (Kuiper \& McHale, 2009), and between maladaptive self-schemas and depression (Dozois, Martin, \& Bieling, 2008). Thus, it would appe ar that humor styles may serve as mediators at one step in the process and later in the process be mediated through other variables. What research may ultimately uncover is a complex connection between fundamental self-attitudes, the views of self that influence how you choose to behave within your social world, your stable assumptions about the world, as reflected in positive personality, and both social and psychological outcome variables. The various pieces of this process have been identified, but the complete chain of events has yet to be tested.

\section{References}

Abel, M. H. (2002). Humor, stress, and coping strategies. Humor, 15, 365-381.

Abel, M. H., \& Maxwell, D. (2002). Humor and affective consequences of a stressful task. Journal of Social and Clinical Psychology, 21, 165-190.

Anagnostopoulos, F., Niakas, D., \& Tountas, Y. (2009). Comparison between exploratory factor-analytic and SEM-based approaches to constructing SF-36 summary scores. Quality of Life Research: An International Journal of Quality of Life Aspects of Treatment, Care \& Rehabilitation, 18, 53-63. 
Anderson, C. A., \& Arnoult, L. H. (1989). An examination of perceived control, humor, irrational beliefs, and positive stress as moderators of the relation between negative stress and health. Basic and Applied Social Psychology, 10, 101-117.

Arbuckle, J. L. (1994-1999). AMOS 4.01 [Software]. Chicago: SmallWaters.

Berk, L. S., \& Tan, S. A. (2009). Mirthful laughter, as adjunct therapy in diabetic care, increases HDL cholesterol and attenuates inflammatory cytokines and hs-CRP and possible CVD risk (abstract). FASEBJ, 23, 990.1, Retrieved from www.fasebj.org.

Berk, L. S., Tan, S. A., Fry, W. F., Napier, B. J., Lee, J. W., Hubbard, R. W., Lewis, J. E., \& Eby, W. C. (1989). Neuroendocrine and stress hormone changes during mirthful laughter. American Journal of the Medical Sciences, 298, 390-396.

Cann, A., Norman, M. A., Welbourne, J. L., \& Calhoun, L. G. (2008). Attachment styles, conflict styles and humour styles: Interrelationships and associations with relationship satisfaction. European Journal of Personality, 22, 131-146.

Cann, A., \& Ełzel, K.C., (2008). Remembering and anticipating stressors: Positive personality mediates the relationship with sense of humor. Humor, 21, 157-178.

Cann, A., Zapata, C. L., \& Davis, H. B. (2009). Positive and negative styles of humor in communication: Evidence for the importance of considering both styles. Communication Quarterly, 57, 452-468.

Cann, A., Zapata, C. L., \& Davis, H. B. (in press). Humor style and relationship satisfaction in dating couples: Perceived versus self-reported humor styles as predictors of satisfaction. Humor.

Carroll, J. L, \& Shmidt, J. L. (1992). Correlation between humorous coping style and health. Psychological Reports, 70, 402.

Carver, C. S., Scheier, M. F., \& Miller, C. J. (2009). Optimism. In S. J. Lopez, and C. R. Snyder (eds.), Oxford handbook of positive psychology (pp. 303-312). New York: Oxford University Press.

Celso, B. G., Ebener, D. J., \& Brkhead, E. J. (2003). Humor, coping, health status, and life satisfaction among older adults residing in assisted living facilities. Aging and Mental Health, 7, 438-445. 
Chen, G., \& Martin, R. A. (2007). A comparison of humor styles, coping humor, and mental health between Chinese and Canadian university students. Humor, 20, 215-234.

Cohen, S., Alper, C. M, Doyle, W. J., Treanor, J. J., \& Turner, R. B. (2006). Positive emotional style predicts resistance to illness after experimental exposure to Rhinovirus or influenza A virus. Psychosomatic Medicine, 68, 809-815.

Cohen, S., Doyle, W.J., Turner, R. B., Alper, C. M., Skoner, D. P. (2003). Emotional style and susceptibility to the common cold. Psychosomatic Medicine, 65, 652-657.

Cohen, S., Kamarck, T., \& Mermelstein R. (1983). A global measure of perceived stress. Journal of Health and Social Behavior, 24, 385-396.

Cohn, M. A., Frederickson, B. L., Brown, S. L., Mikels, J. A., \& Conway, A. M. (2009). Happiness unpacked: Positive emotions increase life satisfaction by building reserves. Emotion, 9, 361-368.

Dozois, D. J. A., Martin, R. A., \& Bieling, P. J. (2008). Early maladaptive schemas and adaptive/maladaptive styles of humor. Cognitive Therapy and Research. Advance online publication. doi: 10.1007/s 10608-008-9223-9.

Frewen, P. A., Brinker, J., Martin, R. A., \& Dozios, D. J. A. (2008). Humor styles and personality-vulnerability to depression. Humor, 21, 179-195.

Friedman, H. S., \& Booth-Kewley, S. (1987). The "disease-prone personality": A metaanalytic view of the construct. American Psychologist, 42, 539-555.

Harrison, L. K., Carroll, D., Burns, V. E., Corkill, A. R., Harrison, C. M., Ring, C., \& Drayson, M. (2000). Cardiov ascular and secretory immunoglobulin A reactions to humorous, exciting, and didactic film presentations. Biological Psychology, 52, 113-126.

Hills, P., \& Argyle, M. (2002). The Oxford Happiness Questionnaire: A compact scale for the measurement of psychological well-being. Personality and Individual Differences, 33, 1073-1082.

Hu, L., \& Bentler, P. M. (1999). Cutoff criteria for fit indexes in covariance structure analysis: Conventional criteria versus new alternatives. Structural Equation Modeling, 6 , $1-55$. 
Hugelshofer, D. S., Kwon, P., Reff, R. C., \& Olson, M. L. (2006). Humour's role in the relation between attributional style and dysphoria. European Journal of Psychology, 20, 325-336.

Janes, L. M., \& Olson, J. M. (2000). Jeer pressure: The behavioral effects of observing ridicule of others. Personality and Social Psychology Bulletin, 26, 474-485.

Kerkkanen, P., Kuiper, N.A., \& Martin, R.A. (2004). Sense of humor, physical health, and well- being at work: A three-year longitudinal study of Finnish police officers. Humor, 17, 21-35.

Kohn, P.M., Lafreniere, K., \& Gurevich, M. (1990). The inventory of college students' recent life experiences: A decontaminated hassles scale for a special population. Journal of Behavioral Medicine, 13, 619-631.

Kuiper, N.A., \& Borowicz-Sibenik, M. (2005). A good sense of humor doesn't always help: Agency and communion as moderators of psychological well-being. Personality and Individual Differences, 38, 365-377.

Kuiper, N. A., Grimshaw, M., Leite, C., \& Kirsh, G. A. (2004). Humor is not always the best medicine: Specific components of sense of humor and psychological well-being. Humor, 17, 135-168.

Kuiper, N. A., \& Harris, A. L. (2009). Humor styles and negative affect as predictors of different components of physical health. Europe's Journal of Psychology, February. Retrieved from http://www.ejop.org/archives/2009/02/humor_styles_an.html

Kuiper, N. A., \& Martin, R.A (1998a). Is sense of humor a positive personality characteristic? In W. Ruch (ed.), The sense of humor: Explorations of a personality characteristic (pp. 159-178). Berlin: Walter de Gruyter.

Kuiper, N. A., \& Martin, R.A (1998b). Laughter and stress in daily life: Relation to positive and negative affect. Motivation and Emotion, 22, 133-153.

Kuiper, N. A., \& McHale, N. (2009). Humor styles as mediators between self-evaluative standards and psychological well-being. The Journal of Psychology, 143, 359-376.

Kuiper, N. A., \& Olinger, L. J. (1998). Humor and mental health. In H. S. Freedman (ed.), Encyclopedia of mental health, vol. 2 (pp.445-457). San Diego: Academic Press. 
Labott, S. M., \& Martin, R. B. (1987). The stress-moderating effects of weeping and humor. Journal of Human Stress, 13, 159-164.

Lefcourt, H. M. (2001). Humor: The psychology of living buoyantly. New York: Kluwer Academic.

Lefcourt, H. M., Davidson-Katz, K., Kueneman, K. (1990). Humor and immune-system functioning. Humor, 3, 305-321.

Lefcourt, H. M., \& Martin, R. A. (1986). Humor and life stress: Antidote to adversity. New York: Springer.

Martin, R.A. (1996). The Situational Humor Response Questionnaire (SHRQ) and Coping Humor Scale (CHS): A decade of research findings. Humor, 9, 251-272.

Martin, R. A. (2001). Humor, laughter, and physical health: Methodological issues and research findings. Psychological Bulletin, 127, 504-519.

Martin, R.A, (2004). Sense of humor and physical health: Theoretical issues, recent findings, and future directions. Humor, 17, 1-19.

Martin, R. A. (2007). The psychology of humor: An integrative approach. New York: Academic Press.

Martin, R.A., Puhlik-Doris, P., Larsen, G., Gray, J., \& Weir, K. (2003) Individual differences in the uses of humor and their relation to psychological well-being: Development of the Humor Styles Questionnaire. Journal of Research in Personality, 37, 48-75.

Nezu, A. M., Nezu, C. M., \& Blissett, S. E. (1988). Sense of humor as a moderator of the relationship between stressful events and psychological distress: A prospective analysis. Journal of Personality and Social Psychology, 54, 520-525.

Njus, D. M., Nitschke, W., \& Bryant, F. B. (1996). Positive affect, negative affect, and the moderating effect of writing on slgA antibody levels. Psychology and Health, 12, 135148.

Osman, A., Barrios, F. X., Longnecker, J., \& Osman, J. R. (1994). Validation of the Inventory of College Students' Recent Life Experiences in an American college sample. Journal of Clinical Psychology, 50, 856-863.

Overholser, J. C. (1992). Sense of humor when coping with life stress. Personality and individual differences, 13, 799-804. 
Pettit, J.W., Kline, J.P., Gencoz, T., Gencoz, F., \& Joiner, T.E. (2001). Are happy people healthier? The specific role of positive affect in predicting self-reported health symptoms. Journal of Research in Personality, 35, 521-536.

Porterfield, A. L. (1987). Does sense of humor moderate the impact of life stress on psychological and physical well-being? Journal of Research in Personality, 21 , 306-317.

Preacher, K. J., \& Hayes, A. F. (2008). Asymptotic and resampling strategies for assessing and comparing indirect effects in multiple mediator models. Behavior Research Methods, 40, 879-891.

Pressman, S. D., \& Cohen, S. (2005). Does positive affect influence health? Psychological Bulletin, 131, 925-971.

Richman, L. S., Kubzansky, L., Maselko, J., Kaw achi, I., Choo, P., \& Baver, M. (2005). Positive emotion and health: Going beyond the negative. Health Psychology, 24, 422429.

Ruch, W., \& Kohler, G. (1999). The measurement of state and trait cheerfulness. In I. Mervielde, I. J. Deary, F. DeFruyt, \& F. Ostendorf (eds.), Personality psychology in Europe (pp. 67-83). Tilburg, Netherlands: Tilburg U niversity Press.

Scheier, M.F., Carver C.S., \& Bridges M.W. (1994) Distinguishing optimism from neuroticism (and trait anxiety, self-mastery, and self-esteem): A reevaluation of the Life Orientation Test. Journal of Personality and Social Psychology, 67, 1063-1078.

Siahpush, M., Spittal, M., \& Singh, G. K. (2008). Happiness and life satisfaction prospectively predict self-rated health, physical health, and the presence of limiting, long-term health conditions. American Journal of Health Promotion, 23, 18-26.

Snyder, S.T., Harris, C., Anderson, J.R., Holleran, S.A., Irving, L.M., Sigmon, S.T., Yoshinobu, L., Gibb, J., Langelle, C. \& Harney, P. (1991). The will and the ways: Development and validation of an individual-differences measure of hope. Journal of Personality and Social Psychology, 60, 570-585.

Svebak, S. (1996). The development of the Sense of Humor Questionnaire: From SHQ to SHQ-6. Humor, 9, 341-361.

Thorson, J. A., \& Powell, F. C. (1993). Development and validation of a multidimensional sense of humor scale. Journal of Clinical Psychology, 49, 13-23. 
Veenhoven, R. (2008). Healthy happiness: Effects of happiness on physical health and the consequences for preventive health care. Journal of Happiness Studies, 9, 449-469.

Ware, J., Snow, K.K., Kosinski, M., \& Gandek, B. (1993). SF-36 Health Survey: Manual and Interpretation Guide. Boston, Mass: The Health Institute, New England Medical Center.

Zillman, D. (1983). Disparagement humor. In P. E. McGhee, \& J. H. Goldstein (eds.), Handbook of humor research (vol. 1, pp. 85-108.). New York: Springer.

About the authors:

Arnie Cann is a professor in the Psychology Department and in the Interdisciplinary Health Psychology Doctoral Program at the University of North Carolina Charlotte. His two main research programs focus on humor and its implications for successful relationships and health, and on posttraumatic growth processes.

Address for correspondence: Prof. Arnie Cann, Department of Psychology, University of North Carolina at Charlotte 9201 Univ ersity City Blvd Charlotte, NC 28223

E-mail: acann@uncc.edu

Kelly Stilwell conducted humor, positive personality and health research with Dr. Cann while completing her psychology degree at the University of North Carolina at Charlotte. She is currently pursuing further graduate studies in counseling at GordonConwell Theological Seminary in Charlotte, NC. Ms. Stilwell's research interests focus on humor, resiliency and psychological health.

Kanako Taku is an assistant professor in the Department of Psychology at Oakland University, Michigan. Her research interests focus on how people may or may not change psychologically after stressful life events, specifically centering on the construct of posttraumatic growth. Her studies have included the areas of clinical, cross-cultural, and statistical psychology. 